\title{
Functional recovery in an urban industrial area - methods and tools to integrate efficiency and sustainability in the pre-design phase
}

\author{
P. Clerici Maestosi ${ }^{1}$, R. Farina ${ }^{1}$, L. Stante ${ }^{1}$, E. Valpreda ${ }^{1}$, \\ A. Parenti ${ }^{2} \&$ I. Stojkov ${ }^{2}$ \\ ${ }^{1}$ ENEA Italian National Agency for New Technologies, Energy and \\ Sustainable Economic Development, Centro Ricerche E. Clementel, \\ Bologna, Italy \\ ${ }^{2}$ University of Napoli, Italy
}

\begin{abstract}
Within the functional recovery project of the urban industrial area which originally hosted British American Tobacco (BAT) in Bologna (1950-2007), the Italian National Agency for New Technologies, Energy and Sustainable Economic Development (ENEA), contributed to identifying priority issues for "responsible design for sustainable energy management". The outlined innovative solutions have been collected in a Technical Annex to tender on "Industrial Research Centre" Design Competition. A comprehensive and holistic approach has been followed in order to develop a framework whereby design solutions can be described in terms of objectives, strategies and targets. Special applications on water balance have been developed to assess water needs, mainly concerning the pre-design phase.
\end{abstract}

Keywords: functional recovery, responsible design, sustainable energy management, technical annex, water balance, needs, assessment.

\section{Introduction}

The choice to develop a "responsible design approach for sustainable energy management for Labs" has taken place within activities carried out by ENEA related to the Regional Research Network for hi-tech industries and, moreover, to the framework of European Funds Program 2007-2011 POR-FRSR (regional project) - due to the setting up of 10 technology and industrial research centers 
in Emilia-Romagna and, moreover, 34 industrial research laboratories, involving a total number of 6 universities and 4 public research centres.

ENEA is involved with four industrial research Labs, which are developing specific actions to build and test tools and methods to supplement and complement each single topic (technological innovation, energy efficiency, seismic safety, sustainable use water, etc.) in order to develop integrated design tools for complex buildings.

The goal for research activity - which involves three ENEA Labs (LAERTE, LECOP, CROSS-TEC [1]) - is to create tools which, according to the rules, enable integrated design mixing technological capabilities, vulnerabilities structural and environmental context [2], and, socio-economic needs.

The object of the research project is the upgrading and renovation of the buildings in which Industrial Research Centre will be located. The buildings originally hosted the British American Tobacco headquarters and production plant.

The building complex (100.000 square $\mathrm{ft}$. in urban area) has been abandoned since a long time.

The refurbishment is supposed to be expensive and difficult to manage in consideration of the final destination of the buildings which does not seem to fit perfectly with the use listed by Superintendence (designer: Luigi Nervi, 1950).

It is thus a multipurpose building, structurally complex, significant and replicable, located in an urban area where construction and refurbishment of high-tech laboratories are intended to realize: a demonstrator of technological innovation, at least for energy efficiency, in compliance with regional laws and expectations; a demonstrator of the opportunity to go beyond, implementing new technologies that, for several reasons, are not yet mature for a full scale application as further applicative research is still needed. So, it will be design not only of buildings but also as a demonstrator of technologies, living research labs.

\section{Meta-design in pre-design phase: methods and tools to fully integrate energy efficiency}

A building, regardless of its intended purpose, acquires economic value if its development is undertaken with Building Process in mind.

The term Building Process (planning (needs assessment), design (consultation of the project manager's team), work execution (quality control), building operation (operation in use)) refers to a structured sequence of steps that start from a needs assessment of clients/end users of building and satisfies those needs through a series of actions in order to ensure design, manufacturing, construction and management of the architectural asset (UNI 10838).

Indeed, innovative methods and design tools are required from the beginning (pre-design phase) by needs for environmental sustainability and energy efficiency. Innovative methods and tools will be useful both during the predesign phase, as well as in the entire design process, to control every single step of decision making. 
The design process [3], which fully outlines a building which is environmentally and energetically sustainable, takes shape through multidisciplinary design specifications, key issues related to territory development, in which the property is located, as well as the construction, operation and use or minimizing use of non-renewable resources, the environmental impact, and general comfort.

The interdisciplinary phase in standard practice of design is called metadesign. It takes place at the beginning of the design phase (preliminary phase) and its objective is management and strategic direction of transition between the inquiry phase of project (data collection and analysis assessment, preliminary design, pre-design phase) and the development of project itself (design).

Therefore a building is not a simple sum of spaces, technical elements, materials and equipment; it is an architectural organism (structured set) (structured set of environmental units/spatial and technological units/technical elements), a system (structured set of spatial elements and technical elements, internal and external, characterized by functions and mutual relations) where each element, relates to each other in complex mode, to give an answer in order to meet certain needs.

The requirement/performance approach (requirements are a request addressed to a particular building element so that it has certain characteristics that meet certain requirements (fixed use conditions and presence of specific external factors). Performance requirement consists of associating each level of satisfaction with technical-scientific parameters, or indication of values to be insured, methods verification and evaluation criteria - using unified procedures of calculation, standardized tests, or unique judging criteria) defines the expected behaviour during the operation-in-use phase, in function of a given technological solution. Characteristics must satisfy the needs of end users, the way of using the building, regulatory requirements and - last, but not least - energy efficiency and environmental sustainability.

There are many instruments monitoring, detection, analysis and definition for stimulating multidisciplinary; all of them useful in the construction process. All discipline draws on those that fulfil the most actors involved in the process (architects, urban planners, installers, etc.).

What is still missing is one tool to guide the preparatory phase (pre-design phase) and the phase of formalization of the project (preliminary design, preliminary design and/or final project), a tool able to cover all the issues in a project using an overall view.

The criteria for sustainability and energy efficiency, besides being the most important if detected at an early stage of preliminary design, allow us to define an overall strategy (macro decisions) to be maintained during the whole course of the design process, and to establish those requirements which, assessed in a comprehensive multidisciplinary logic, will help to fully define the architectural organism, according to previous decisions.

The case study which has been proposed focuses on the opportunity of innovation regarding the development of assessment tools. 
Yet, identified tools are determinant if placed in a dynamic innovative management planning process, which aims to create a vision and shared objectives, transforming the work of individual practitioners in a team and using the tools to promote multidisciplinary content, sharing of options, the identification of mutual relations between the individual choices. An important factor was the creation of a tool that promotes the organization of individual practitioners/experts, allowing the identification of choices, developing scenarios in a perspective of overall multidisciplinary.

Behind the development of the method there is the creation of a model investigation, a model of data acquisition, data analysis model, a model for scenarios development (based multidisciplinary), as well as the creation of a tool box.

The opportunity to develop a tool box is represented by the need for designing sustainable water uses, which - in practice - is hardly ever the input data (requirements) in a design process. On the other hand, it is the result of specific choice developed in other technical areas (mechanical, electrical, regulatory constraints, etc.).

\section{Water and wastewater management and reuse in civil buildings}

In the design process of a building assigned to civil use a big relevance is given to the performances that will be guaranteed in terms of energetic efficiency or seismic resistance.

The same attention is not normally given instead to the design of the water distribution systems and especially to the local wastewater collection systems.

Actual Italian and European rules are mainly focused on the protection of the environment from pollution and on urban flood protection than on water consumption reduction and reuse. In fact, only very general indications are given on the necessity to stimulate the reduction of the drinking water supplied by the network and on the possibility of using lower quality water for non-drinking purposes.

In this direction Italy is probably the only country in Europe that has issued a decree, DM185/2003 that defines the possibility and limits of the use of reclaimed water in all the economic sectors: municipal, industrial, and agricultural. In this decree, attention is strongly focused on the protection of hygiene and the health of the citizen and the environment, but that, in the end, discourages the use of reclaimed wastewater.

Moreover it is necessary to consider that the price of water in Italy is relatively low compared to other countries: that also discourages us from acting towards water use reductions, and even worse if we talk about water reuse, as the payback period for the investment could be very long.

As a last point, it is necessary to consider that UNI-EN norms establish a minimal performance for taps. This performance is established as litres of water supplied per minute and the suggestion is at least $5 \mathrm{l} / \mathrm{min}$. If this was considered a good parameter twenty years ago, now, with the development of the 
technology applied to taps, it is clear that it is possible to have a good washing performance even with lower water flow rates. Probably it is time to change the rule. Or it should be.

On the other hand, talking about the removal of wastewater produced inside the building or collected from roofs or yards, there are only few regulatory indications: to avoid mixing rain water with wastewater, and, during storm events, to collect and treat the first $5 \mathrm{~mm}$ of rain in a period of 15 minutes and guarantee a draining flow directed to surface waters according to the legislation.

During the development of the proposal for the design competition of the Bologna Industrial Research Center particular attention was given to the possibility of reducing water consumption in the building [4], stimulating the use of technologies with lower water use, and analysing all the possibilities of access to those inputs that nowadays are defined as new water sources, and their possible and appropriate uses.

The first analysis undertaken has been focused on the different types of water that could possibly be recovered from the building. According to this analysis it was possible to identify 5 available sources of reusable water of different qualities.

These types of water are: grey water from washbasins and showers, rain water from roofs, rain water from outdoor areas, waste water from softener systems and reverse osmosis, and clean water produced by laboratory activities.

In this first step the water cycle of the laboratories was not considered as, though laboratories do not always need high quality water, and the discharge is not always deeply polluted water that cannot be reused or that requires special disposal system, in this first phase it was still too difficult to define the right amount of water consumed and the possibilities for the reuse. This is an analysis that will be undertaken in the future when the activities that each laboratory will develop in the new centre will be better defined.

For the other kinds of water, a deep analysis has been done according to their quality, their harvesting and conservation means and the possible and more appropriate treatments that would suite future needs and uses.

According to Italian legislation and the large availability, the treated grey water has been assigned to toilet flushing, and the eventual excess to the irrigation of the outside green areas. The use of treated grey water for the irrigation of the green areas has been done for two reasons. The first is because the health risk for building occupants is very low. The second is that grey water is always available, even during dry periods, and it is more economic if compared to the necessity of storing and conserving rainwater for long periods.

On the other hand, rainwater normally has a higher quality than grey water as water harvested from roofs has a better quality compared to the water collected from internal streets and footpaths. For this reason, water collected from roofs is suitable for example for the cleaning of the floors where it is not necessary to employ drinking water.

The remaining water collected could be used to realize a recreational area which could be able to generate a mitigation point especially for the summer season. 
A special request addressing the possible evolutions that the research activities on by-products recovery and on any water reuse has been proposed for the future building activities. To facilitate the analysis of wastewater generated from the different uses in terms of flows, total amounts and quality, a design request has been made: all the pipe outputs from washbasins and other sanitary installations should not be directly collected to one point, but kept separated as much as possible to give the opportunity to apply the most appropriate treatment to every single flow, or identify the flows that can be treated together because of their similar characteristics.

Special attention is given also to the segregation of black water. In particular, a part of the building will be with toilets with a double collection system, faeces and urine. In this way it is possible to further reduce the use of water, and it will be possible to collect two different flows: one rich in organic compounds, useful for carbon recovery. The second flow, generated from urine and richer in salts, especially nitrogen that can be treated for the recovery of nitrogen as a fertilizer.

A last relevant point is that in this way it will be easier to manage and control the pollution arising from the pharmaceuticals that in this moment is one of the major challenges that research in the wastewater treatment field is facing.

\section{Water balance and water needs assessment}

The outcome of the working relationship between ENEA and an in house society held by Bologna Municipality, Province and Emilia-Romagna Region, brought the awareness that energy efficiency issues can be transferred to a wider vision, to develop the idea of an overall efficiency of the building which should be well integrated in a holistic, territorially oriented perspective.

The hypothesis to develop methods, guidelines and tools for a structured approach to the pre-design phase is intended to develop decisions which impact on the facility performance in the area of efficiency and social and environmental sustainability.

As the fields of design [5] and management [6] evolve, there is an increasing understanding that simply specifying "good" technologies or design features to achieve desired performance is not sufficient.

Efforts to do so are often thwarted by the absence of explicit direction from the owner, by misunderstandings and conflicting visions among the members of the design team, and by ambiguities imposed by a lack of measurable performance targets.

Therefore, a comprehensive and holistic approach has been built in order to develop a framework whereby design solutions can be described in terms of objectives (overall goals), subordinated strategies (specific means of achieving goals) and targets (measurable performance targets). The first application has been a water assessment action plan. 


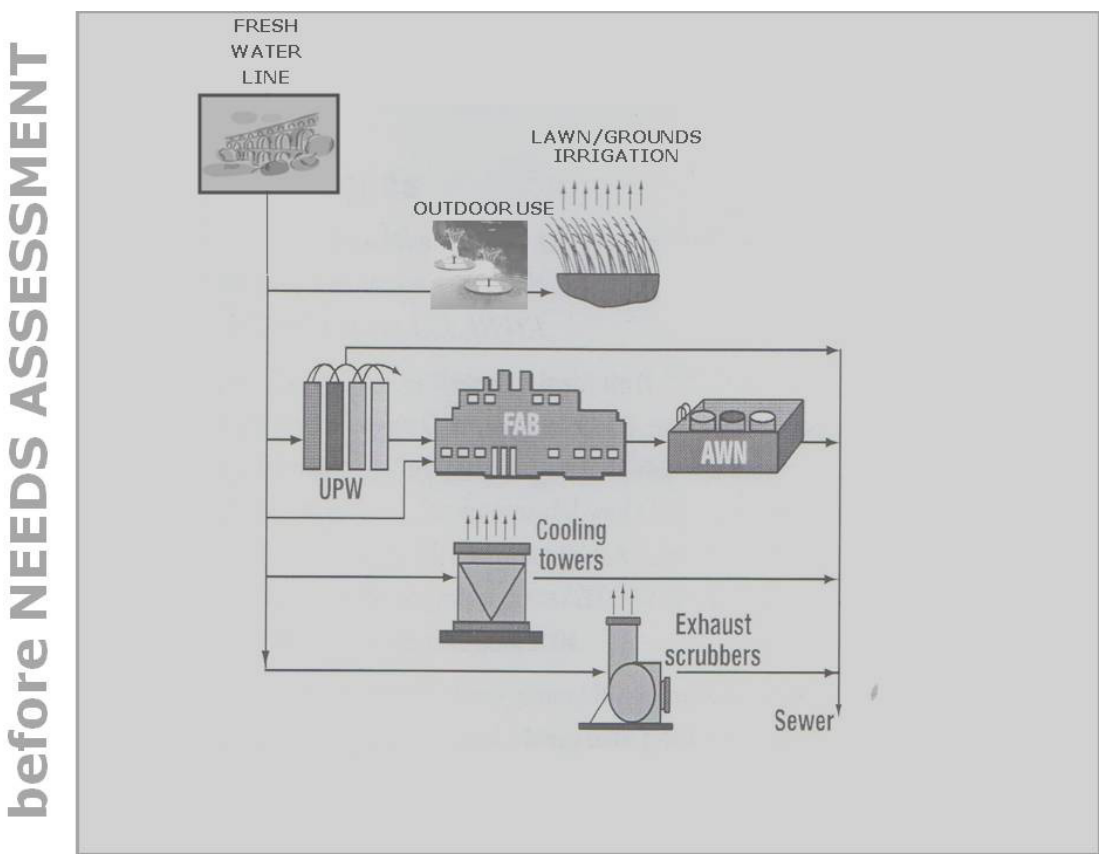

Figure 1: $\quad$ Structured approach in pre-design phase before needs assessment.

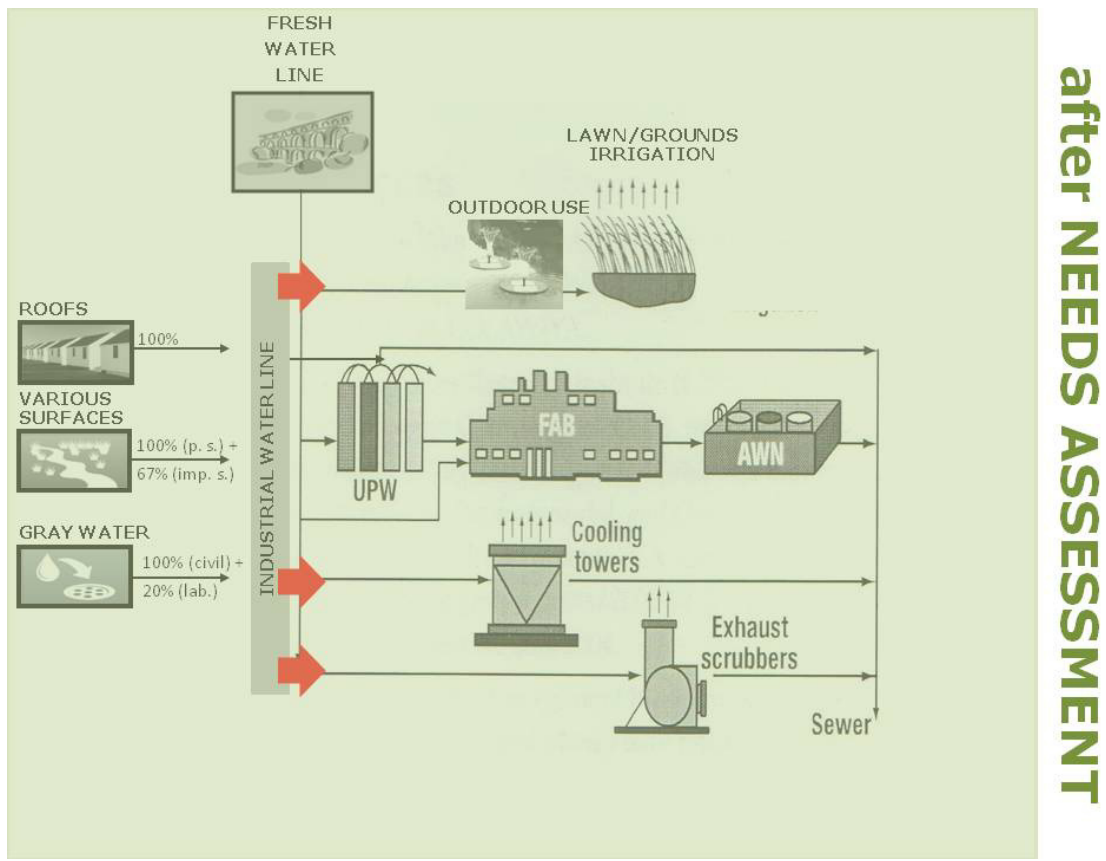

Figure 2: $\quad$ Structured approach in pre-design phase after needs assessment. 
A water balance has been developed to assess water needs. The first step has been to document all major water-using equipment and processes or usage amounts: a specific inquiry tool has been set, enabling to record data useful in next assess phase.

Then has been set a tool enabling to rank input data and to develop scenarios.

The water quality required for each use has been included, as well as information about local climate, such as monthly averages for evapotranspiration rate, relative humidity, temperature, and precipitations.

Then the last step has been to set a tool to look for opportunities of greater efficiency in each major usage category and determine whether water from one process can be used elsewhere cost-effectively.

It is believed that tools set up for water assessment in Industrial Research Labs could be useful in all type of civil buildings. In fact an Industrial Research Centre needs more water to meet process and cooling loads, among other requirements, they usually use much more water per square foot than conventional commercial buildings do.

\subsection{Research centre: integrability factors}

In order to integrate water management solutions in the design process of Bologna Industrial Research Centre - combining the physical/social/economic layout of the surrounding area with the control of the water cycle - the research has established a system of reference for integrability.

The system is divided into: goals, connected to the water sector to constraints given by call for tender, as well as by regulatory in force; strategies and targets to reach the objectives; integrability factors, relating to each single strategy (the "reference system" developed is based on an innovative methodological approach. It starts from strategic level and arrives to design).

Integrability factors are changeable elements of architectural asset such as natural, technical-constructive, as well as social and economic, which must be integrated in technology systems to sustainable management of water resources.

Each factor is listed (priority level), in relation to the feasibility and effectiveness of the strategy linked to it.

The priority level depends on the relationship with the strategy (direct or indirect), flexibility factor degrees (high, medium, low, zero), adaptability of available technologies.

An in-depth analysis of high priority factors has enabled us to verify the feasibility of the strategies that can be implemented in the design phase of an Industrial Research Centre and to measure (using performance indicators) potential levels of need satisfaction.

Under the framework defined by the tender notice and by architectural rules and regulations in force, research has been suggested to increase the objectives and strategies required by the aforesaid regulations, in order to optimize the use and management of all the available water resources and achieve various benefits. Through the integration of all the aspects of the complex relationship between water and the built environment, water was at the heart of the project. 


\subsection{Refurbishment: restriction and resources}

Local factors may constitute a constraint or an opportunity to the implementation and integration of certain strategies and projects, aimed at an efficient and sustainable use of water resources in Bologna Industrial Research Laboratories. Taking into account the location (urban area) and requirements set by the tender, high priority integrability factors have been identified and analysed, both in quantity and quality.

Specifically, to achieve significant water saving and reduction of environmental burdens, the research focused on the factors related to the strategies for: grey and rain water recovery, low consumption devices, runoff containment, soil permeability.

On the basis of the constraints and requirements implied by existing regulations, as well as by local environmental conditions and by the system of planned activities of Bologna Industrial Research Laboratories, we defined criteria and assessment methods for the consistency and characteristics of the roofing and the external areas, water supply and consumption, sewer systems, and rainfall data.

For instance, the analysis of the cover was designed to identify potential rainfall surfaces, paying particular attention to the conservation constraints given by the historical-artistic nature of the building complex.

The analysis of the exteriors aimed at identifying both potential areas of ground level rainwater collection and any compatible external use of recovered and treated water (grey and rainwater).

The indications obtained through this study are to be understood as minimum requirements designers should follow to achieve the objectives related to the sustainable management of water resources. As called for by the tender notice, the acquired information is to be intended less as numerical connotations (sq. $\mathrm{ft}$. standard) than as performance indicators.

\subsection{Rainfall data}

A detailed understanding of local climate conditions and rainfall characteristics is essential to making statements about the possibility of collecting and managing rainwater in the studied area and is also important to develop contaminant-loading evaluations and potential rainwater harvesting.

In Italy, designers are asked to face the problem of pollution in urban runoff by regional legislation, which requires that the first flush flood, which is the initial surface runoff (valued as the first $5 \mathrm{~mm}$ that falls during a rainstorm after a dry period, for Emilia-Romagna), has to be treated, given that it is supposed to contain higher pollutant concentrations than subsequent ones.

For the purpose of this research, rainfall records for the city of Bologna, obtained in a mm/hour format from ARPA (Regional Agency for Prevention and the Environment of Emilia-Romagna) were tested on a 6-year time period (2005-2010) and were then organized to gain information about quantity and variability. 
Later on, the rainfall data collected during the study were entered into an Excel $^{\mathrm{TM}}$ worksheet and were filtered and grouped in order to have monthly and annual key trends (Table 1).

To summarize, these calculations suggested an average rainfall of $726 \mathrm{~mm}$ on "clean" surfaces and $490 \mathrm{~mm}$ of rain that can be collected from polluted surfaces $\left(1 / \mathrm{m}^{2}\right)$, by removing the first $5 \mathrm{~mm}$ after a $24 \mathrm{~h}$ (at least) dry period.

\subsection{Water needs and scenarios}

A system of knowledge developed through assessment of integrability factors, has enabled to outline alternative scenarios on use and management of water resources in Bologna Industrial Research Laboratories.

Table 1: $\quad$ Monthly (av.) rainfall distribution.

\begin{tabular}{|c|c|c|c|c|c|c|c|}
\hline \multicolumn{7}{|c|}{ Average rainfall (time period: years 2005-2010) } \\
\hline Month & $\begin{array}{c}\text { mm } \\
\text { of } \\
\text { rain } \\
\left(\mathbf{l} / \mathbf{m}^{\mathbf{2}}\right)\end{array}$ & $\begin{array}{c}\text { Dry } \\
\text { hours }\end{array}$ & $\begin{array}{c}\text { Rainy } \\
\text { hours }\end{array}$ & $\begin{array}{c}\text { Total } \\
\text { hours }\end{array}$ & $\begin{array}{c}\text { Max } \\
\text { consequent } \\
\text { dry hours }\end{array}$ & $\begin{array}{c}\text { Number } \\
\text { of 24h dry } \\
\text { periods }\end{array}$ & $\begin{array}{c}\text { mm after } \\
\text { removing } \\
\text { the first } \\
\text { flood 5 mm }\end{array}$ \\
\cline { 3 - 8 } & & & & & & & \\
\hline JANUARY & 40.2 & 678.0 & 57.2 & 735.2 & 277.0 & 4.0 & 22.9 \\
\hline FEBRUARY & 49.9 & 604.3 & 70.0 & 674.3 & 346.5 & 3.2 & 33.2 \\
\hline MARCH & 67.6 & 670.7 & 69.5 & 740.2 & 336.7 & 4.5 & 49.0 \\
\hline APRIL & 62.2 & 664.3 & 55.3 & 719.7 & 179.5 & 4.8 & 38.7 \\
\hline MAY & 68.3 & 675.5 & 40.0 & 715.5 & 342.3 & 4.3 & 46.2 \\
\hline JUNE & 75.0 & 604.7 & 30.7 & 635.3 & 256.2 & 3.2 & 55.1 \\
\hline JULY & 24.6 & 729.2 & 12.3 & 741.5 & 483.8 & 3.0 & 11.8 \\
\hline AUGUST & 43.4 & 719.7 & 21.5 & 741.2 & 368.8 & 3.8 & 19.7 \\
\hline SEPTEMBER & 69.9 & 686.3 & 33.7 & 720.0 & 288.2 & 3.8 & 51.6 \\
\hline OCTOBER & 82.8 & 685.8 & 58.0 & 743.8 & 395.2 & 2.8 & 68.7 \\
\hline NOVEMBER & 84.1 & 637.3 & 69.0 & 706.3 & 244.7 & 4.8 & 61.3 \\
\hline DECEMBER & 58.6 & 659.0 & 75.0 & 734.0 & 196.5 & 5.3 & 31.9 \\
\hline & & & & & & & \\
\hline AVERAGE & 60.5 & 667.9 & 49.3 & 717.3 & 309.6 & 4.0 & 40.8 \\
\hline (mOnth): & 60.9 & $\mathbf{3 0 1 7}$ & $\mathbf{4 7}$ & $\mathbf{4 9 0}$ \\
\hline
\end{tabular}

The scenarios are configured as a possible mix of measures and actions, capable of simulating the obtained results on the basis of objectives. For this purpose, possible systems of water supply (compared to water input), compatible uses and treatments (compared to the output destination), and last water discharge were summarised.

To "measure" the obtained results, in terms of water savings and reduction of environmental loads, first it was necessary to examine the indoor and outdoor water needs.

Considering the annual average consumptions, different according to different uses and users, the difficulties arise from the lack of benchmarks and homogeneous parameters.

The difficulties increase further if the project units, as in the case of Bologna Industrial Research Laboratories, contain not only functions that can be categorized as "common" (offices, recreational services, housing services, ...) 
but also "specialised" functions (research laboratories), which require a clear knowledge of the used procedures and laboratory tools. For these reasons, a series of criteria and specific tools (online survey), were defined to evaluation of indoor and outdoor water needs.

The comparison of data on water need with those on water recovery sources has enabled to define three scenarios for a sustainable use and management of water resources.

Through the performance indicators, it is possible to compare the results obtained for all scenarios (water savings and reduction of environmental loads) applying different strategies of reuse, different technological solutions for water treatment and different solutions for the external areas characterization.

The overall sustainability of scenarios must be further verified in relation to all the solutions, at the network level, subnet, central, related to distribution, accumulation, disposal of water.

These solutions weigh heavily on cost factor for which should be appropriately assessed.

The choice of the types of treatment was dictated by the desire to promote purification systems that can bring the space and improve the overall quality of the same, while the association use compatible/provenance water recovery was as also the time factor, which affects the availability of rainwater during the year and on request water for irrigation. Scenarios allow you to select different technological options, and propose as models to be confronted in their implementation with the interaction between all the factors involved. They express the complexity of internal relations to a system of feedback between the variable.

\section{Conclusions}

ENEA worked from the early stage of the tender to write a draft for Technical Annex which illustrated ENEA's approach and suggested practical ways to introduce the integration from the early phase of design.

Thereafter ENEA has developed the research, which is still ongoing, focusing on development of tools that geared both to public and private stakeholders - to accompany towards an integrated planning, both to the Government institutions (local and regional level), to support and facilitate the assessment of the suitability of a project to the needs, vulnerabilities and expectations of efficiency and environmental sustainability, based on clear criteria.

The environment is, therefore, the approach of ENEA survey. The environment as intrinsic element of design, fundamental for the assessment of energy efficiency, even in logic of redefinition of the energy model of the city itself.

The current research provides, in following steps, to cover socio-cultural aspects of the building process that will involve, in a short time, our society.

Specifically ENEA intends to develop topics related to new technologies to manage "intelligent" building complexes, according to the instance of smart buildings and smart cities. 


\section{References}

[1] LECOP: Laboratorio per l'Ambiente; LAERTE: Efficienza energetica e sicurezza; CROSS-TEC: ICT e virtualizzazione di reti di impresa; TRACCIABILITA': Tecniche spettrometriche applicate agli alimenti ed all'ambiente.

[2] A. Zitelli, S. Boato, E. Valpreda, Blue in architecture - symposium proceedings, Adaptation to climate change: land, social and environmental processes in the Northern Adriatic Sea area, Univ. Iuav di Venezia, 2009.

[3] P. Clerici Maestosi, La manutenzione nel processo edilizio, Alinea: Firenze, 2005.

[4] B. Failla, M. Spadoni, L. Stante, E. Cimatti, G. Bortone, The aquasave project: An innovative water saving system in a residential building. IAHSAISH Publication: Italy, 2001, (121-126).

[5] M.P. Arredi, Progettare:metodi, tecniche, norme e realizzazioni, Edilizia per uffici, P. Clerici Maestosi, Manutenzione e riconversione degli immobili (Chapter.10.1), UTET: Torino, 2005.

[6] F. Terranova, Edilizia per la Sanità, P. Clerici Maestosi, Orientamenti progettuali nelle ristrutturazioni e interventi manutentivi (Chapter 7), UTET: Torino, 2005.

[7] PROTECTA, numero speciale dicembre 2010 "Casambiente ed Ecobuilding”, P. Clerici Maestosi, C. Meloni, Human oriented technology per l'ecosistema urban, Ecoedizioni internazionali, Roma, 2011. 